\title{
Erratum: Dacryocystectomy for Chronic Dacryocystitis in a Beagle Dog
}

A) Check for updates

\section{Youngseok Jeong \\ Songhui Lee ${ }^{1}$ \\ Su An Kim ${ }^{1}$ \\ Sangho $\mathrm{Woo}^{2}$ \\ Dumin $\mathrm{Go}^{2}$ \\ Kangmoon Seo \\ Seonmi Kang ${ }^{1, *}$}

'Department of Veterinary Clinical Sciences, College of Veterinary Medicine and Research Institute for Veterinary Science, Seoul National University, Seoul 08826,

Korea

${ }^{2}$ Department of Veterinary Pathology,

College of Veterinary Medicine and

Research Institute for Veterinary Science

Seoul National University, Seoul 08826,

Korea

*Correspondence: yorong4@snu.ac.kr

\section{ORCID}

Youngseok Jeong:

https://orcid.org/0000-0002-6646-8277

Songhui Lee:

https://orcid.org/0000-0002-1826-8924

Su An Kim:

https://orcid.org/0000-0002-1572-1260

Sangho Woo:

https://orcid.org/0000-0002-5779-8127

Dumin Go:

https://orcid.org/0000-0001-8924-7197

Kangmoon Seo:

https://orcid.org/0000-0001-6645-7116

Seonmi Kang:

https://orcid.org/0000-0001-8017-0891

Copyright $\odot$ The Korean Society of Veterinary Clinics
J Vet Clin 38(3): 152-158 (2021)

https://doi.org/10.17555/jvc.2021.38.3.152

Notification on spelling errors in the co-author's name:

'Dumin Ko' was changed to 'Dumin Go' due to incorrect spelling of the English name of the co-author, written in p.152 of this paper. 